\title{
RESENHA
}

SANTOS, Edméa. Pesquisa-formação na Cibercultura. Santo Tirso, Portugal: Whitebooks, 2014.

Tania Lucía Maddalena ${ }^{1}$

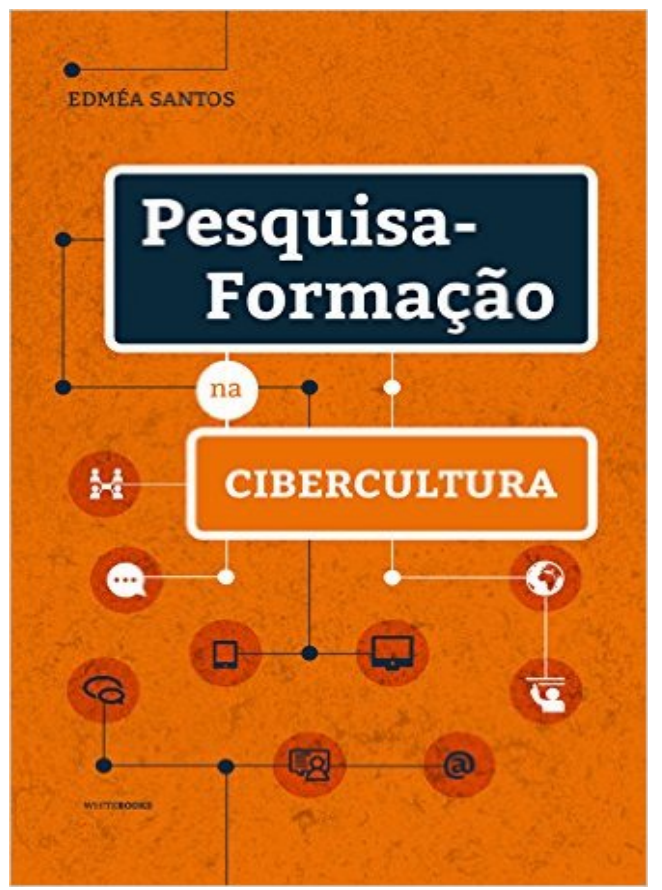

livro "Pesquisa-Formação na Cibercultura", publicado em 2014, é de autoria de Edméa Oliveira dos Santos, professora adjunta da Faculdade de Educação -UERJ. Atua no Programa de Pós-graduação em Educação, Proped-UERJ. Líder do Grupo de Pesquisa Docência e Cibercultura - GpDoC, da mesma universidade, há mais de 15 anos, vem desenvolvendo pesquisas na área de educação e cibercultura, formação inicial e continuada de professores e pesquisadores, informática na educação, educação

online, EAD, currículo, didática e práticas pedagógicas.

O livro, de 172 páginas, foi classificado como $L 4^{2}$ na última avaliação da CAPES e está dividido em quatro capítulos que narram o entendimento da autora sobre a "pesquisaformação" como metodologia de pesquisa na nossa cultura contemporânea: a cibercultura.

\footnotetext{
1 Doutoranda em Educação no Proped-UERJ, membro do Grupo de pesquisa Docência e Cibercultura (GPDOC/UERJ). Mestre em Educação pela UNICAMP. Especialista em Educação e Novas Tecnologias pela FLACSO - Argentina, e Bacharel em Ciências da Educação pela UNLP - Argentina. E-mail: tlmaddalena@gmail.com

${ }^{2}$ L4 é a nota máxima de qualidade na avaliação de livros pela CAPES.
} 


\section{Revista Docência e Cibercultura}

Já na apresentação, a autora delineia alguns posicionamentos que se expandirão ao longo da leitura da obra e que são significativamente importantes para o seu entendimento. A saber:

- A cibercultura é compreendida como cultura contemporânea, na qual a comunicação, a produção e circulação em rede de informações e conhecimentos se dão na interface cidade-ciberespaço, emergindo assim novos arranjos espaçotemporais e, com eles, novas práticas educativas e de formação.

- A pesquisa no contexto da cibercultura requer imersão nessas práticas. Os sujeitos da pesquisa são entendidos como "praticantes culturais" que produzem dados em rede, portanto, não são interpretados como meros informantes, mas sim como coautores já que produzem cultura.

- Não existe pesquisa-formação desarticulada do contexto da docência. Isso é enfatizado, ao longo do texto. Há grande investimento, por parte da autora e do GpDoC, em articular pesquisa e docência, tendo a cibercultura como campo de pesquisa. Assim sendo, a educação online é contexto, campo de pesquisa e dispositivo formativo.

- A Educação online não é definitivamente a evolução das práticas massivas de EAD. Portanto, não há separação entre os contextos educativos das cidades e seus equipamentos culturais, como escolas, universidades, movimentos sociais, museus, organizações, eventos científicos e demais redes educativas em que estão imersas.

Após esses delineamentos básicos que contextualizam a proposta do livro, tem início o Capítulo 1 - A cena sociotécnica: cibercultura em tempos de mobilidade ubíqua - com a epígrafe "O tamanho do meu mundo é do tamanho da minha linguagem" (Ludwig Wittgenstein), um convite à reflexão sobre os potenciais da mobilidade ubíqua na cibercultura em sua fase Web 2.0.

Para chegar a essa fase, a autora apresenta a evolução da Web 1.0, na qual a convergência das tecnologias informáticas com as tecnologias das telecomunicações limitava o acesso à Internet, cujos mecanismos centravam-se no desktop, o que exigia uma conexão fixa e física do computador a uma linha telefônica, rádio, banda larga. Para se 


\section{Revista Docência e Cibercultura}

comunicarem em rede, os seres humanos ficavam com seus corpos estáticos diante de seus computadores.

A fim de descrever o mecanismo das práticas e usos da Internet nessa fase, a autora lança mão de dois conceitos próprios da informática como metáforas para ilustrar a relação dicotômica entre ciberespaço e espaços urbanos: $(a)$ download - transposição de conteúdos da Internet para o computador e (b) upload - transposição de conteúdos do computador para a Internet. Inicialmente os professores, usuários e até grandes mídias de massa utilizavam essas lógicas transformando a Internet num grande repositório de conteúdos. Mas, com a popularização da linguagem HTML e suas interfaces, passaram a utilizá-la para além da busca de informações, desenvolvendo práticas de criação sob o formato de de homepages, websites pessoais ou institucionais.

A princípio, a rede foi habitada pelos professores os quais publicavam seus planos de cursos, conteúdos de aprendizagem, tarefas, entre outros. Num segundo momento, esses usuários investiram na autoria dos estudantes, instigando-os também a compartilharem suas produções.

Na cibercultura atual, a mobilidade integra potência à essa dinâmica por possibilitar a conexão com o ciberespaço em espaços geograficamente dispersos a partir do uso de dispositivos móveis, como smartphones e tablets. Nessa perspectiva, a autora enfatiza a necessidade de um forte investimento na formação para a docência online, com vistas à criação, mediação e ampliação de repertórios culturais no contexto cibercultural de mobilidade, ubiquidade e autorias nas redes.

No Capítulo 2 - Pesquisar na cibercultura: a educação online como contexto -, é apresentada a noção de educação online (EOL) como contexto e fenômeno da cibercultura e não como mera "evolução" das práticas da EAD convencionais. Essa tese defendida pela autora e seu grupo de pesquisa - o GpDoC, há mais de 10 anos, é fundante nessa obra.

A autora argumenta que mesmo com a evolução da Internet e os ambientes online, os programas de EaD mudaram suas aparências, porém continuam mantendo a mesma lógica tradicional da mídia de massa, mantendo a lógica da transmissão e da autoaprendizagem. Então, embora o suporte seja digital e online, as práticas pedagógicas apenas sofrem uma transposição das antigas práticas de EaD, por isso não podem ser

\begin{tabular}{l|l|l} 
v.1 & n.1
\end{tabular}




\section{Revista Docência e Cibercultura}

consideradas como educação online. Muito pelo contrário, são concepções extremamentes diferentes, na medida em que a segunda possui metodologia própria a qual pode inspirar mudanças profundas no modelo de transmissão.

A educação online constitui, portanto, uma emergência da cibercultura que, por sua vez, tem como fundamentos o hipertexto e a interatividade e impõe uma nova reconfiguração social, cultural, econômica e política ao colocar em xeque o esquema clássico da informação com o polo de emissão liberado, abrindo espaço para o diálogo e a participação colaborativa.

Qual é a caraterística distintiva da educação online? O que muda em relação à EaD? indaga a autora. Nessa ambiência supracitada, o sujeito, além do aprendizado direto com o conteúdo, circula por diferentes interfaces, em mobilidade e em interação com outros sujeitos, de forma síncrona e assíncrona. Aqui o conceito de "distância" entra em conflito, porque a ubiquidade e a mobilidade proporcionam novas experiências que desafiam esse distanciamento entre professores, mediadores, estudantes e os diversos conteúdos hipermediais.

Esses ambientes virtuais de aprendizagem (AVA) agregam a convergência de mídias, ou seja, possuem a capacidade de hibridizar, em um único ambiente, várias mídias com uma multiplicidade de linguagens, como: sons, imagens, vídeos, gráficos e textos em geral. A autoria de recursos nessas linguagens, a colaboração entre sujeitos e a circulação pelas diversas interfaces são caraterísticas fundantes da educação on-line.

No Capítulo 3 - Pesquisa-formação na cibercultura: fundamentos e dispositivos, a autora apresenta os fundamentos para o exercício da pesquisa-formação, a partir da abordagem multirreferencial com os cotidianos na cibercultura. Também traz o entendimento da formação docente na contemporaneidade, enfatizando o "paradigma da epistemologia da prática" e a multirreferencialidade, no diálogo com autores como: Nóvoa (1995-2002), Tardif (2002), Josso (2004), Macedo (1998-2008), Ardoino (1998-2003), entre outros. A epistemologia da prática reconhece o saber oriundo e reconstruído nas práticas docentes, pois, a experiência docente e toda a produção de saberes em torno dela são o objeto de estudo e alimento de inspiração, "nesses estudos, interessa saber como os 


\title{
Revista Docência e Cibercultura
}

professores integram esses saberes a suas práticas, os produzem, transformam e os ressignificam no seio do seu trabalho" (D’ÁVILA, 2008, p.33-34).

Tendo em vista esta forma de fazer docente, a pesquisa-formação multirreferencial como método de pesquisa, não separa pesquisa de ensino. Nesta forma "outra" de pesquisar e de fazer política, existe uma ação deliberada de transformação da realidade já que a pesquisa-formação possui um duplo objetivo: transformar a realidade e produzir conhecimentos relativos a essas transformações. A multirreferencialidade é utilizada ao longo do capítulo para contemplar, nesses espaços de aprendizagem...

\begin{abstract}
Uma leitura plural de seus objetos (práticos ou teóricos), sob diferentes pontos de vista, que implicam tanto visões específicas quanto linguagens apropriadas às descrições exigidas, em função de sistemas de referenciais distintos, considerados, reconhecidos explicitamente como não redutíveis uns aos outros, ou seja, heterogêneos (ARDOINO, 1998, p.24).
\end{abstract}

A autora alerta que muitos dos cursos de formação docente possuem em seus currículos uma dicotomia entre teoria e prática já que os estudantes só vão realizar os estágios nas instituições educativas nos últimos anos do curso, porém como afirma Paulo Freire, "não existe docência sem discência". Docentes e discentes aprendem juntos, formando-se no contexto cultural, histórico e social em que essa relação acontece, sendo vital compreender a prática docente para além da racionalidade técnica, mas como uma fonte de conhecimentos e espaçotempo privilegiado para fazer pesquisa. Nesse sentido, a autora enfatiza que o objeto não pode ser analisado por um método previamente definido, concebendo a pesquisa com base "na implicação do pesquisador com o campo de pesquisa, construindo juntamente com os sujeitos envolvidos o conhecimento e o próprio método" (SANTOS, 2014, p. 92). Corrobora, dessa forma, o pensamento de Morin (2003, p. 20), para quem "o método não precede a experiência; o método emerge durante a experiência e se apresenta ao final, talvez para uma nova viagem".

Esse método já possui um histórico de experiências de pesquisa em educação online e aprendizagem ubíqua bem-sucedidas as quais vêm sendo desenvolvidas pela autora e seu grupo de pesquisa. Algumas dessas e perspectivamente seus dispositivos de pesquisaformação na cibercultura aparecem como fechamento da obra, no Capítulo 4 - Pesquisaformação na cibercultura: invenções. 


\section{Revista Docência e Cibercultura}

A autora destaca três novas pesquisas que foram desenvolvidas em seguida à sua pesquisa de doutorado (SANTOS, 2005) junto ao GpDoC, que atualizam e consolidam a metodologia da pesquisa-formação na cibercultura. Santos apresenta os dispositivos criados, bem como experiências de práticas pedagógicas que se gestaram a partir deles.

Para fins dessa obra, opta por compartilhar narrativas advindas da primeira pesquisa vivenciada na Universidade do Estado do Rio de Janeiro (UERJ), onde foi investigado quais e como são edificados os saberes docentes no contexto das práticas pedagógicas e da formação de professores-tutores desta universidade. Mergulhando nesse contexto, Santos sintetiza a referida pesquisa e seus desdobramentos, trazendo as narrativas de atores e autores do processo formativo como professores-coordenadores, tutores, estudantes em fóruns, AVA, chats, entre outros. Ressalta que na mediação online, o docente é provocador de novas situações de aprendizagem interativas e colaborativas e é o que potencializa essa modalidade, deixando como fruto práticas colaborativas nas quais todos envolvidos no processo são coautores do produto final.

O segundo dispositivo abordado é o cineclub e as conversas online como imagens e narrativas na pesquisa-formação na cibercultura. O terceiro, é a metodologia da Webquest interativa na educação online e, por fim, o último dispositivo trata-se de um case com o Twitter e as potencialidades de pesquisar em mobilidade ubíqua.

As experiências pedagógicas de educação online e seus dispositivos são evidentes exemplos de pesquisa-formação no contexto cibercultural, nos quais o professorpesquisador não é apenas quem constata o que ocorre, mas também aquele que intervém como sujeito de ocorrências. Ser sujeito de ocorrências, no contexto de pesquisa e prática pedagógica, implica conceber a pesquisa-formação como processo de produção de conhecimentos sobre problemas vividos pelo sujeito em sua ação docente. A pesquisaformação contempla a possibilidade da mudança das práticas docentes, bem como dos sujeitos em formação. Assim, "a pessoa é, simultaneamente, objeto e sujeito da formação" (NÓVOA, 2004, p.15). 


\section{Revista Docência e Cibercultura}

É notório a implicância da autora em trazer o GpDoC ao longo da obra, demarcando um coletivo que pesquisa-forma em sintonia com a cultura contemporânea. Ao longo dos 10 anos do grupo, as pesquisas desenvolvidas buscam compreender a formação nos espaçostempos da cibercultura, sempre mergulhando nas potencialidades das tecnologias digitais em rede. O desenho de diversos dispositivos de formação é o grande ganho desse grupo de pesquisa, que ao longo dos últimos anos desenvolveu experiências e ambiências formativas em educação online, na formação do formador, nas interfaces cidadeciberespaço, com cibervídeos, Storytelling e no último tempo com forte investimento no App-learning ${ }^{3}$, posicionando-se assim, como grupo de referência nas práticas de pesquisaformação na cibercultura.

\section{REFERÊNCIAS}

ARDOINO, J. Abordagem multirreferencial (plural) das situações educativas e formativas. In: Barbosa, J. Multirreferencialidade nas ciências e na educação.(pp. 24- 51). São Carlos: EdUFSCar, 1998.

D’ÁVILA, C. Formação docente na contemporaneidade: limites e desafios. Revista da FAEEBA: Educação e Contemporaneidade, Salvador, v.17, n. 30, p. 33-43, jul./dez. 2008.

MORIN, E., CIURANA, E., MOTTA, R. Educar na era planetária. O pensamento complexo como método da aprendizagem pelo erro e incerteza humana. São Paulo: Cortez; Brasília, DF:UNESCO, 2003.

NÓVOA, A. Prefácio. In: JOSSO, Marie-Christine. Experiências de vida e formação. São Paulo: Cortez Editora, 2004, p. 11-34.

SANTOS, E. Educação on-line, Cibercultura e Pesquisa-formação na prática docente. Tese de doutorado em Educação, Universidade Federal da Bahia, 2005.

. Pesquisa-formação na cibercultura. Santo Tirso, Portugal: Whitebooks, 2014

\footnotetext{
${ }^{3}$ App-learning são práticas de aprendizagem mediadas por interfaces digitais, específicamente aplicativos de celulares e tablets, que potencializam experiências formativas comunicacionais interativas, hipertextuais e em mobilidade.
} 